\title{
Editorial
}

\section{Social capital in primary health care}

The ownership of capital is considered an advantage, and social capital may be viewed, simplistically, as the advantage gained by an individual or a group of individuals (such as a community) as a result of being part of a social network (Hean et al., 2002). An elderly patient being given a lift to a surgery by her daughter, for example, has received practical support by virtue of the fact that she is part of a family network. It is not only practical support that is gained this way, however. An isolated parent, who has no friends to commiserate with the difficulties in coping with a young crying baby, for example, is at a disadvantage compared to the person who can tap into informational, emotional and social support, quite apart from any practical help that may be available. At a more general level, there is an advantage for those living in communities where everyone knows and trusts their neighbours, extending a helping hand in times of need in the realistic expectation that, when the situation is reversed, the favour will be returned.

At this quite simple level, these situations will be very familiar to anyone working in primary health care. They are not only markers of advantage (or not) but are practical examples of social inequalities that influence health. It is well recognized that service use in areas or by individuals vary according to the kinds of family and social networks available, and their accompanying local mores and norms. The activities of promoting and developing trusting, supportive networks as local resources are considered essential by some in primary care, like health visitors or community development workers (Cowley and Billings, 1999a). However, such activities have, at times, been considered somewhat peripheral to the 'main business' of professional health care, which may be characterized as the diagnosis, treatment and care of people with medical problems (Cowley and Billings, 1999b). Even when prevention of such problems is recognized, the ability to demonstrate any beneficial health outcomes from the rather amorphous socially-focused, family and community-wide activities has been constrained by inadequate research methodologies. There is a lack of explanatory theories to show precisely how and where such a vast and poorly-defined range of interactions might be expected to influence health. This lack, in turn, has prevented clarity in defining and developing practical interventions that can be both implemented in primary care and evaluated in a robust way.

Developments in the field of social capital offer the promise of an emerging theoretical base within which explanatory research and effective interventions could become possible. A discussion paper prepared for the British Cabinet Office (Performance and Innovation Unit (PIU), 2002) described the 'explosion of interest' and exponential growth in academic publications in social relationships, norms and networks since about 1995, along with a plethora of definitions. In view of this, the PIU warn that caution is needed, because of mis-specification or ambiguity in some of the models used in the empirical literature. Nevertheless, they conclude that 'overall, the evidence described in this paper from a range of sources using a variety of methods for the beneficial effects of social capital is impressive' (PIU, 2002, p 5).

In a recent project funded by the English Health Development Agency, we tried to avoid the problems that arise from ambiguous research. Before developing and validating an instrument suited to measuring the social capital generated in formal groups and projects, we carried out an in-depth analysis of the concept (Hean et al., 2002). We looked, first, at the use and meaning of social, then of capital, then the two words together. This process showed that attributes of social capital may be global, in that they apply to the whole concept, or they may be dimensions that do not apply in all circumstances. Globally, it is clear that social capital exists in or through social relationships; it is 
dynamic, durable and can be defined by its functions, such as facilitating action, encouraging cooperation or increasing trust. Putnam (2000), for example, identifies the functions of bonding social capital, the so-called 'social glue' holding the strong bonds that form between family members or those belonging to a particular club, close friendship group or support network and of bridging social capital. The latter is characterized as the 'social oil' that lubricates the less dense but more cross-cutting ties, perhaps with work colleagues or acquaintances in a local community.

Social capital is multidimensional, which gives rise to some of the confusion that can arise about the nature of the concept. We found a number of individual components of social capital in the literature that do not describe the concept when considered alone. Instead, they describe dimensions involved in its practical application: the generation and use of social capital. The main dimensions are network characteristics, such as frequency of participation or heterogeneity of a network, and affective measures such as cohesion, identity with other members, a sense of empowerment and trust. Norms and rules that govern actions in social networks, including a sense of reciprocity and social support, are also considered in much of the literature. Kawachi (2001), for example, explains that many researchers, searching for indicators of social capital, have analyzed secondary datasets concentrating on attributes such as the density of membership in civic associations, interpersonal trust, and perceptions of reciprocity. Such studies have revealed increasing evidence of the relationship between social capital and health inequalities, which accounts for much of the current political interest in the concept.

However, this tendency to focus on only one dimension of social capital, such as trust, social support or network participation, is one reason for criticisms about ambiguities in the research or that the concept offers nothing new to social theory. Thus, single dimensions need to be considered in conjunction with the global attributes if they are to represent social capital or provide a basis for evaluation of activities. Also, to distinguish it from other social theories, it is important to remember that social capital is capital. Capital is something dynamic that continually changes from one form to the next and has a tendency to accumulate and endure.
If a project has the aim of improving social capital in postnatally depressed mothers, for example, then describing the project in terms of social support alone implies a one-dimensional exchange whereby help is given by one person to another. However:

- if effective support is provided in a context that fosters trust in the project and its members;

- if this increase in trust encourages some women to continue participation in this group or in other groups (like friendship networks) or take up other civic activities in the neighbourhood;

- if the increase in trust, in turn, increases the level of involvement of the women, perhaps motivating them into taking on a leadership role within this or other groups;

- if the norms of extending support to new mothers become established in a local area, beyond the group itself.

then one has described a process whereby emotions, attitudes, events and outcomes are linked in a dynamic and sustainable chain. This process describes social capital in action and provides a theoretical base from which robust, evaluative research can be developed.

In summary, there is increasing evidence from studies of social capital and health that community trust and networks can improve population health, and an associated increase in explanatory theory that could underpin robust research. The excitement shown by the increase in academic publications has been widely matched by the number of social action projects and initiatives in Britain today, including those within the Health Development Agency Social Capital Programme, which funded the study cited above. However, the promise of significant improvements in population health is unlikely to be fulfilled as long as such activities continue to be seen as exceptional 'special projects.' Instead, it is time to reassert the longrecognized importance of participation and community involvement in health as a core pillar of all primary health care (Macdonald 1992, World Health Organization, 1978), with social capital as a key marker of its success.

Sarah Cowley (correspondent) Professor of Community Practice Development, King's College London, James Clerk Maxwell, Building, 57 Waterloo Road, London UK Email: sarah.cowley@kcl.ac.uk 
Sarah Hean

Senior Research Fellow, University of Southampton, School of Nursing and Midwifery, University Road, Highfield, Southampton UK

\section{References}

Cowley, S. and Billings, J. 1999a: Resources revisited: salutogenesis from a lay perspective. Journal of Advanced Nursing 29, 994-1005.

Cowley, S. and Billings, J. 1999b: Implementing new health visiting services through action research: an analysis of process Journal of Advanced Nursing 30, 965-974.

Hean, S., Cowley, S., Forbes, A., Griffiths, P. and Murrells, T.
2002: An examination of the potential to identify an instrument reflecting measurable attributes of social capital - final report. London: Florence Nightingale School of Nursing and Midwifery King's College, Research Report to Health Development Agency.

Kawachi, I. 2001: Social capital for health and human development: Health and poverty in a social context. The Society for International Development 44, 31-35.

Policy Innovation Unit 2002: Social Capital: A Discussion Paper. London: Performance And Innovation Unit, Cabinet Office.

Putnam 2000: Bowling alone: the collapse and revival of American community. New York: Simon and Schuster.

Macdonald, J. 1992: Primary health care: medicine in its place. London: Earthscan Publications.

World Health Organization 1978: Primary Health Care: Report of the international conference on primary health care, AlmaAta USSR 1978. Geneva: World Health Organization.

\title{
Primary Health Care Research and Development - Online access
}

\begin{abstract}
s online
The abstracts and key words of each issue of Primary Health Care Research and Development are available to view online free of charge - often in advance of the paper publication. Please sign in as a guest on the ingenta website if you are not already an institutional subscriber:

www.ingenta.com
\end{abstract}

\section{Full text download}

Institutional subscribers are also able to download the full text of each article. Once payment has been made to Turpin Distribution Services (see subscription details), the online registration form should be completed at:

\section{www.ingenta.com/home/fs_registernow.htm}

Please have your customer number available. A username and password will then be allocated to allow you to gain access to the full text of articles via the ingenta website. Alternatively contact:

Email: help@ingenta.com

\section{Home page}

The journal home page is available at:

$$
\text { www.phcrd.com }
$$

The Terms and Conditions of use together with a list of intermediaries through which the journal is also available can be found on the Arnold website:

$$
\text { www.arnoldpublishers.com/journals }
$$

